\title{
A mediação do Pacto Nacional pelo Fortalecimento do Ensino Médio (Pnem) na Gerência Regional de Educação (Gered) de Chapecó, SC: a percepção do orientador de estudo*
}

\author{
Sandra Maria Zardo Morescho ${ }^{\mathrm{I}, \text { II }}$ \\ Nadir Castilho Delizoicov ${ }^{\mathrm{III}, \mathrm{IV}}$
}

http://dx.doi.org/10.24109/2176-6681.rbep.100i255.4126

\footnotetext{
*om modificações e acréscimos de novos dados, este texto foi apresentado na $38^{\mathrm{a}}$ Reunião Científica da Associação Nacional de Pós-Graduação e Pesquisa em Educação (Anped), em 2017.

I Universidade de Passo Fundo (UPF). Passo Fundo, Rio Grande do Sul, Brasil. E-mail: <samaza@unochapeco. edu.br $>$, <https://orcid. org/0000-0001-9714-1552>.

II Doutoranda em Educação, com auxílio bolsa PROSUC/ CAPES, Modalidade II, na Universidade de Passo Fundo (UPF). Passo Fundo, Rio Grande do Sul, Brasil..

III Universidade Federal de Santa Catarina (UFSC). Florianópolis, Santa Catarina, Brasil. E-mail: <ridanc.nadir@gmail. com $>$, < https://orcid. org/0000-0003-3642-8298>.

IV Doutora em Educação pela Universidade Federal de Santa Catarina (UFSC). Florianópolis, Santa Catarina, Brasil.
}

\section{Resumo}

Este artigo apresenta dados de pesquisa qualitativa sobre a formação continuada de professores ofertada pelo Pacto Nacional pelo Fortalecimento do Ensino Médio (Pnem). Investiga as percepções dos orientadores de estudo sobre a formação realizada em 2014 e 2015, com professores do ensino médio. Os dados foram obtidos em entrevistas semiestruturadas, com 12 orientadores de estudo que mediaram a formação aos docentes de 10 escolas da Gerência Regional de Educação (Gered) de Chapecó, Santa Catarina. A análise dos dados aborda a formação dos orientadores, a mobilização dos docentes para participarem do Pnem, a interrupção do programa, as dificuldades enfrentadas e as mudanças observadas. Os resultados indicaram que os orientadores reconheceram a significância do Pnem para a formação docente, pois o programa mudou o cotidiano escolar e contribuiu para o reconhecimento do estudante como sujeito no processo de ensino-aprendizagem.

Palavras-chave: Pnem; orientador de estudo; formação continuada do professor. 


\author{
Abstract \\ The mediation of the National Pact for High School Strengthening on \\ the Regional Educational Administration of Chapecó, SC: the perception \\ of study supervisors
}

This article presents research data on teachers' continuing education offered by the National Pact for High School Strengthening (Pnem). A qualitative study was conducted to investigate the study supervisors' perceptions on high school teachers' continuing education in 2014 and 2015. The data were obtained in semi-structured interviews with twelve study supervisors who oversaw the teachers' education in ten schools of the Regional Educational Administration of Chapecó, in western Santa Catarina State. The data analysis presents: the study supervisors' education; the mobilization of teachers to take part in the National Pact for High School Strengthening; difficulties confronted; changes observed and the interruption of the program. The results indicate that the study supervisors recognized the program's importance for the teachers' education, since it led to positive changes in school's daily life while contributing to the recognition of the students' significant role in the teaching-learning process.

Keywords: Pnem; study supervisor; teacher's continuing education.

\title{
Resumen
}

La mediación del Pacto Nacional por el Fortalecimiento de la Enseñanza Secundaria (Pnem) en la Gerencia Regional de Educación (Gered) de Chapecó, SC: la percepción del orientador de estudio

Este artículo presenta datos de investigación cualitativa a respecto de la formación continua de profesores ofertada por el Pacto Nacional por el Fortalecimiento de la Enseñanza Secundaria (Pnem). Investiga las percepciones de los orientadores del estudio sobre la formación realizada en 2014 y 2015, con profesores de la enseñanza secundaria. Los datos fueron obtenidos en entrevistas semiestructuradas con 12 orientadores de estudio que mediaron la formación a los docentes de 10 escuelas de la Gerencia Regional de Educación (Gered) de Chapecó, Santa Catarina. El análisis de los datos aborda la formación de los orientadores, la movilización de los docentes para participar del Pacto Nacional por el Fortalecimiento de la Enseñanza Secundaria, la interrupción del programa, las dificultades enfrentadas y los cambios observados. Los resultados indicaron que los orientadores reconocieron la significancia del programa para la formación docente, pues el programa cambió el cotidiano escolar y aportó para el reconocimiento del estudiante como sujeto en el proceso de enseñanza-aprendizaje.

Palabras clave: Pnem; orientador de estudio; formación continua del profesor. 


\section{Introdução}

O texto apresenta parte dos resultados de uma pesquisa que investigou as percepções de orientadores de estudo sobre o processo de formação continuada promovido pelo Pacto Nacional pelo Fortalecimento do Ensino Médio (Pnem), ofertado em diferentes estados brasileiros em 2014 e 2015. Os orientadores de estudo mediaram a formação para professores do ensino médio. Na época deste trabalho, esses sujeitos atuavam em escolas públicas da rede estadual de ensino de Santa Catarina, pertencentes à Gerência de Ensino (Gered) de Chapecó. ${ }^{1}$

Considerando a formação continuada como um processo reflexivo, no qual o docente tem a oportunidade de reconhecer a sua condição de inacabamento e a necessidade de formação permanente, faz-se necessário oportunizar a ele condições para participar de processos formativos ao longo da carreira. Nessa perspectiva, apresentamos o Pnem como um processo de formação permanente, sistematicamente organizado e implementado, lamentavelmente, por um período de apenas dois anos. Assim, são discutidas informações sobre a formação dos orientadores de estudo, a mobilização dos docentes para participarem do Pnem, as dificuldades enfrentadas, as mudanças observadas e a interrupção do programa diante da reforma do ensino médio.

\section{A significância da formação continuada para a docência}

O exercício da docência constitui uma tarefa com especificidades que exigem conhecimentos, compromissos e responsabilidades, pois, conforme destaca Mizukami (1996, p. 60), "o professor é o principal mediador entre os conhecimentos socialmente construídos e os alunos". Para a autora, os processos que envolvem o aprender a ensinar e o aprender a profissão, ou seja, o aprender a ser professor, são de longa duração e envolvem a prática da sala de aula e os processos formativos, entre outros.

A formação inicial para o exercício da docência constitui, segundo advertem Gatti, Barreto e André (2011), a base da atividade educativa que envolve a profissionalidade e a profissionalização do professor. Para André (2010), os professores reconhecem a necessidade de um aprendizado contínuo ao longo da carreira docente e, para tanto, devem se envolver em processos de formação intencionalmente planejados com o propósito de contribuir para transformar a prática em sala de aula.

Diante do exposto, é imprescindível destacar a pertinência da formação

Os dados fazem parte de dissertação de mestrado Formação continuada de professores: a percepção do orientador de estudo sobre o Pnem na Gered de Chapecó, defendida no Programa de Pós-Graduação stricto sensu em Educação da Universidade Comunitária da Região de Chapecó (Unochapecó). do professor, sendo que esta não possui um estágio final preestabelecido. Candau (1996) diz que a formação de professores precisa ser repensada, tanto a inicial quanto a continuada, pois ambas são imprescindíveis ao longo da profissão docente. A autora considera, ainda, que a escola constitui o principal espaço para tal fim e que deve ser vista como o locus da formação continuada.

O professor, ao longo da carreira, reflete sobre a ação e para a ação (Silva; Araújo, 2005). Essas reflexões possibilitam modificações de saberes, 
bem como a transformação de práticas e, ainda, permitem que o professor se conscientize sobre a sua condição de inacabamento. Tudo isso porque

\begin{abstract}
o homem pode refletir sobre si mesmo e colocar-se num determinado momento, numa certa realidade: é um ser na busca constante de ser mais e, como pode fazer esta autorreflexão, pode descobrir-se como um ser inacabado, que está em constante busca (Freire, 1979, p. 27).
\end{abstract}

Freire (1996) chama a atenção para o fato de que a formação humana ocorre ao longo da vida do sujeito, considerando, assim, a sua condição de inacabamento, pois o ser humano está em construção permanente. Essa premissa remete também à formação do professor num processo permanente de aprendizado ao longo da carreira.

\title{
O Pnem: as percepções dos orientadores de estudo
}

O Pnem, instituído pela Portaria $\mathrm{n}^{\circ} 1.140$, de 22 de novembro de 2013, em uma parceria entre o Ministério da Educação (MEC) e as Secretarias Estaduais e Distrital de Educação, teve como compromisso a formação continuada dos professores e coordenadores atuantes no ensino médio de escolas públicas, rediscutindo e atualizando as práticas docentes em conformidade com as Diretrizes Curriculares Nacionais do Ensino Médio (Brasil. MEC, 2013).

A formação ofertada pelo Pacto teve como tema "Sujeitos do Ensino Médio e Formação Humana Integral" (Brasil. MEC, [s.d.]), e foi desenvolvida na modalidade presencial nas escolas de atuação dos professores de ensino médio. Durante o Pnem, os estudos direcionaram-se à articulação entre conhecimentos das diferentes disciplinas e áreas, a partir da realidade escolar, seguindo as orientações das citadas Diretrizes, as quais requerem que os professores "ampliem suas compreensões sobre a totalidade dos componentes curriculares, na forma de disciplinas e outras possibilidades de organização do conhecimento escolar" (Brasil. MEC. SEB, 2014, p. 4).

Durante a vigência do Pnem, discutiu-se a formação integral do aluno do ensino médio e a necessidade de identificar aspectos de sua realidade, assim como de suas necessidades, para relacioná-los ao conteúdo. Considerar o estudante no processo ensino-aprendizagem, reconhecendo que ele possui vivência e conhecimentos construídos além da escola, é, como propõe Freire (1996), respeitar os saberes dos sujeitos, discutindo criticamente a realidade por eles vivenciada, possibilitando a compreensão e o entendimento do modo como ela se organiza.

Ainda durante o Pnem, foram os orientadores de estudo que mediaram a formação aos professores do ensino médio. A escolha desses agentes ocorreu por meio de processo seletivo nas respectivas escolas, atendendo aos requisitos da Portaria $\mathrm{n}^{0}$ 1.140/2013 (Brasil. MEC, 2013).

Na coleta de dados da pesquisa, foram feitos contatos com as instituições responsáveis pela oferta do Pacto na cidade definida como campo de estudo. Na Gered de Chapecó, SC, vinculada à Secretaria Estadual 
de Educação, obteve-se a relação das escolas que ofertam o ensino médio e que estiveram envolvidas com o Pnem. Participaram da formação 28 escolas de ensino médio e, destas, foram selecionadas para o trabalho 10 que comportavam o maior número de profissionais envolvidos na formação. Os dados da pesquisa (Zardo Morescho, 2017) foram coletados por meio de entrevistas semiestruturadas, com 12 orientadores de estudo selecionados, sendo que em duas escolas a formação foi mediada por dois deles, devido ao alto número de professores participantes, cerca de 40 sujeitos.

Os orientadores de estudo eram efetivos em escolas de ensino médio da rede estadual de ensino de Santa Catarina, pertencentes à Gered de Chapecó, com carga semanal de 40 horas-aula. As funções que desempenhavam variavam entre assistente técnico-pedagógico, orientador educacional, assistente de educação e professor, com tempo de serviço entre 10 e 32 anos. Todos possuíam licenciatura plena, seguida de especialização, sendo que dois entrevistados eram mestres, um em história e o outro em educação.

Os dados estão organizados no texto segundo as seguintes categorias: formação dos orientadores de estudo, mobilização dos docentes para participarem do Pnem, dificuldades enfrentadas, mudanças observadas e interrupção do Pnem.

\section{A formação do orientador de estudo}

Na cidade de realização da pesquisa, os orientadores de estudo participaram de um processo formativo coordenado pelo formador regional do Pnem, designado para a Gered de Chapecó, e com a contribuição de docentes da Universidade Federal da Fronteira Sul (UFSS), Campus de Chapecó, SC (Zardo Morescho, 2017).

Segundo os orientadores de estudo $(\mathrm{OE}){ }^{2}$ a formação recebida foi criteriosamente desenvolvida. Os encontros de formação foram realizados periodicamente: "Havia um cronograma em que a gente geralmente sabia quando iria ser o encontro" (OE5); "Os encontros eram mensais, às vezes, até duas vezes por mês" (OE7). Além disso, possibilitavam a troca de conhecimentos e informações entre o formador regional e os orientadores de estudo, de modo que todos os professores de ensino médio participantes do Pacto estudassem os mesmos temas/conceitos ao longo do processo.

Destacando o empenho, a seriedade e a responsabilidade do formador regional, alguns orientadores de estudo entrevistados consideraram, entre os pontos negativos, que a formação recebida foi breve: "A formação foi boa, mas o tempo, insuficiente. Deveria ter mais tempo [...] para a discussão e aprofundar os conteúdos" (OE12). Os orientadores entrevistados estavam cientes de que a formação do Pnem se processou em rede: os docentes da universidade formavam o formador regional, e este formava o orientador de estudo que, posteriormente, atuava junto aos professores do ensino médio: "Nessa rede de formação, eram os formadores regionais que formavam, a partir de outra formação que recebiam, e, depois, chegava até a gente, e considero que se perdeu muito no caminho" (OE1). Nesse 
sentido, os orientadores manifestaram o desejo de maior contato com os docentes da universidade durante sua formação: "Acredito que teria sido mais significativo se em alguns encontros a gente pudesse também estar em contato com esses profissionais das instituições de ensino superior. Eu acredito que a gente teria conseguido avançar mais, aprofundar mais" (OE1).

Durante o Pnem, os orientadores de estudo relataram que surgiram dificuldades em relação a alguns temas mais complexos que, posteriormente, seriam trabalhados com o grupo de professores da unidade escolar: "O formador nos tratava muito bem, acessível, deu as orientações, mas não de conteúdo [...], de passar conhecimento mesmo" (OE5). A brevidade da formação recebida pelo formador regional foi considerada uma limitação diante das dificuldades enfrentadas no momento de o orientador de estudo trabalhar com os docentes nas escolas.

Pela complexidade de alguns temas, os orientadores de estudo mencionaram que, quando "tinham [...] dificuldades, [...] chamavam os professores das áreas do conhecimento para auxiliar" (OE7), e "Quando percebiam que colegas do grupo dominavam alguns assuntos, pediam ajuda a eles [...], isso enriqueceu muito o nosso grupo. Tínhamos pessoas muito qualificadas" (OE5). No entanto, mesmo diante das dificuldades e do desejo de maior contato com docentes da universidade, os orientadores de estudo reconheceram a necessidade e a importância de um esforço individual e/ ou coletivo para estudar e avançar: "de repente, precisamos evoluir mais e aprender talvez a ler e a nos formar enquanto grupo, sozinhos" (OE1). Essa ação repercutiu nas escolas, o que induziu à colaboração e à socialização dos professores das diferentes áreas do conhecimento.

Para Candau (1996), quando a formação continuada é centrada na escola, a prática reflexiva contribui para a identificação de problemas existentes e de possíveis soluções. Essas ações, segundo Araújo, Araújo e Silva (2015), contradizem propostas de formação continuada que se baseiam na concepção liberal-conservadora, conhecida como racionalidade técnica, que se opõe ao processo crítico-reflexivo. A formação continuada vai além da aquisição de informações divulgadas em cursos, treinamento, palestras, seminários, encontros, oficinas, conferências, que se afastam de processos problematizadores e reflexivos.

Ao desejarem uma formação mais aprofundada, os orientadores de estudo deixaram evidente o reconhecimento de sua condição de inacabamento. $\mathrm{O}$ ato de ensinar, como uma especificidade humana, requer que o educador esteja seguro no momento em que vai interagir com o outro (Freire, 1996).

\section{A mobilização dos docentes}

Para os orientadores de estudo, os fatores que mobilizaram os professores a participarem do Pnem foram o reconhecimento da necessidade da formação continuada, a bolsa de estudo e o certificado. O diálogo com os docentes da unidade escolar para a apresentação do programa e seus objetivos também foi fundamental para a adesão deles: "Falamos da 
importância da formação, das novas políticas que estavam se apresentando para o ensino médio e da necessidade de conhecer [...] nosso aluno para saber como desenvolver um trabalho melhor daqui para frente" (OE6).

Além de a bolsa de estudo ser considerada um incentivo, o certificado de 200 horas contribuiu para a participação dos professores. Dentre o grupo, havia vários casos de professores que, mesmo sem serem bolsistas, realizaram a formação, com interesse no certificado, que seria utilizado posteriormente em processos seletivos de ingresso no magistério por aqueles que são Admitidos em Caráter Temporário (ACTs) e para a ascensão profissional dos efetivos da rede estadual de ensino de Santa Catarina: "penso que $50 \%$ dos professores fariam a formação mesmo sem a bolsa [...], outro fator é a questão das horas de curso e o certificado [...]. São fatores que influenciam" (OE10).

A oferta da formação continuada para o professor do ensino médio foi inédita, uma vez que, geralmente, é direcionada aos professores que atuam no ensino fundamental: "para o ensino médio não havia essa preocupação em parar, fazer um estudo, pensar nessa atualidade, como o ensino médio está, quais os problemas enfrentados" (OE4). A importância da formação continuada também foi abordada pelos orientadores de estudo no momento em que mobilizavam os professores a participarem do Pnem:

[...] conversei, com os professores que a formação continuada é uma necessidade. E uma fala constante entre os professores [...]. Esta era uma oportunidade interessante, pois não ouviríamos uma palestra de alguém que vinha de fora, mas sim iríamos construir nossas próprias ideias (OE9).

Após a mobilização dos docentes do ensino médio para o Pnem, os orientadores de estudo enfrentaram uma série de desafios, conforme consta a seguir.

\section{Desafios do orientador de estudo}

Durante o processo formativo do Pnem, o orientador de estudo enfrentou dificuldades, tais como ajuste dos horários para a realização dos encontros com os professores, resistência de alguns em comparecer à escola além de sua carga horária e interrupção da formação entre a primeira e a segunda etapa.

Embora houvesse a orientação para que o Pnem fosse realizado dentro da carga horária dos professores, a definição do horário foi polêmica, diante das dificuldades em reunir todos os docentes ao mesmo tempo para o planejamento. Assim, a formação teve de ser realizada em vários momentos, ou seja, no período noturno, aos sábados e nos intervalos entre os turnos vespertino e noturno, indo além da carga horária do professor. A definição dos horários foi discutida com os docentes, porém a dificuldade persistia com alguns que se mostravam resistentes em frequentar a escola além de sua carga horária de trabalho: "Às vezes, tivemos dificuldade em 
conciliar o dia, conciliar o horário da formação [...]. Fora do horário, cada um tinha suas particularidades, e tivemos um pouco de dificuldade nessa questão" (OE5).

Uma das causas apontadas pelos orientadores de estudo relacionadas à resistência do professor em frequentar a escola além do horário de trabalho se deve ao descontentamento diante da falta de reconhecimento da profissão docente. A questão é traduzida, entre outros fatores, pela desvalorização salarial:

A carga horária do professor é significativa, e ele tem vida fora da escola. Quem trabalha 40 horas, normalmente, trabalha 40 aulas por semana. Então teria que se dedicar a mais leituras e mais um período semanal. Então observo que essas foram as principais dificuldades (OE1).

A primeira etapa do Pnem foi realizada no segundo semestre de 2014. Nesse período, de acordo com os orientadores de estudo, os professores mostravam-se muito envolvidos, motivados, empolgados e comprometidos com as atividades, dando um retorno significativo: "O projeto iniciou em 2014 e teve uma parada no mês de janeiro, as discussões e o estudo dos cadernos estavam muito interessantes [...], os professores estavam participando com empenho e energia muito boa" (OE9).

Na segunda etapa da formação, realizada em 2015, após o período de férias, os orientadores de estudo identificaram que o rendimento dos professores decaiu, pois a motivação e o empenho da primeira etapa não estavam mais presentes: "No início de 2015, tivemos dificuldades no sentido de motivar o grupo, que, antes da parada, estava motivado e, no momento de 2015, foi difícil motivá-lo novamente" (OE9).

Para os orientadores de estudo, as razões que dificultaram os professores a manter o mesmo desempenho de 2014 referem-se a demandas da escola, características de início do ano letivo. Incluem-se, entre elas, novo planejamento, novos alunos, novos projetos a serem trabalhados, atividades que exigem tempo e empenho dos docentes.

A interrupção entre a primeira e a segunda etapa do Pnem ocasionou dificuldades para envolver o grupo novamente. "Então, o retomar cabe ao orientador [...], retomar o incentivo, com ânimo, com argumentos e trazer o grupo de volta" (OE10). Apesar das dificuldades que se constituíram desafios a serem superados, foi reconhecida a significância do Pnem, testemunhada por mudanças que se processaram nas escolas e na prática pedagógica dos professores que dele participaram, apresentadas a seguir.

\section{Mudanças observadas com a realização do Pnem}

Depois da realização das duas etapas da formação, em 2014 e em 2015, os orientadores de estudo afirmaram que o Pnem contribuiu para mudanças significativas nas escolas em que foi realizado, principalmente na sala de aula, na adaptação curricular, na avaliação e reconhecimento do papel de sujeito do estudante do ensino médio. 
Destaca-se que o Pnem proporcionou, também, maior aproximação entre os professores, ação que contribuiu para o fortalecimento do grupo: "Com a formação, houve uma união bastante grande entre os professores [...], o coletivo melhorou muito [...]" (OE5). Essa aproximação proporcionou a troca de informações sobre os conteúdos trabalhados com os estudantes, mediante diálogo, contribuindo para mudanças significativas no processo de ensino e aprendizagem: "[...] era um momento que proporcionava o diálogo, onde o professor conseguia trocar algumas informações com os demais para saberem o que estariam trabalhando e o que poderiam trabalhar juntos" (OE1).

Durante a formação, as aulas eram planejadas coletivamente. Professores que ministravam diferentes componentes curriculares de uma mesma área do conhecimento ou de áreas distintas planejavam desenvolver um trabalho conjunto com os conteúdos que tinham relação entre si. A adaptação curricular permitiu que o estudante relacionasse os temas trabalhados com mais de um componente curricular, ação que se materializou num trabalho interdisciplinar: "A maioria conseguiu captar esse novo olhar, adaptar de maneira diferente suas metodologias [...] através da interdisciplinaridade" (OE8).

Os orientadores de estudo relataram, ainda, mudanças na avaliação do estudante do ensino médio, que passou a ser realizada de modo diferenciado, pois o caderno de estudo do Pnem, correspondente ao tema avaliação (Brasil. MEC. SEB, 2013b), recomendava que esta ocorresse durante o desenvolvimento do programa curricular, ao mesmo tempo que o professor revisasse suas estratégias, realizando ajustes nas atividades e no planejamento. Essas ações induzem ao reconhecimento do estudante do ensino médio como sujeito no processo de aprendizagem, identificando seus progressos e dificuldades. É preciso que a avaliação seja compreendida como um instrumento para o alcance do êxito dos estudantes, considerando, inclusive, sua individualidade. É desejável que o aluno reconheça o processo avaliativo como um instrumento que está a serviço de sua aprendizagem, constituindo-se como ponto de apoio para interferências futuras, considerando suas fragilidades, limites e potencialidades para a intervenção do professor (Brasil. MEC. SEB, 2013b). Tanto as modificações na metodologia quanto no modo de avaliar foram observadas pelos orientadores de estudo:

[...] o Pnem trouxe um crescimento, um amadurecimento, para muitos professores que dele participaram. Amadureceram no sentido da avaliação. O caderno da avaliação foi riquíssimo. Teríamos que ter mais cadernos que trabalhassem a formação voltada à avaliação. (OE11).

O Pnem cooperou para o reconhecimento da importância de a escola considerar o estudante do ensino médio como sujeito que vivencia uma determinada realidade, que tem sua individualidade e que possui uma vida fora da escola:

Tiveram professores que falaram para mim que, a partir das leituras que fizeram sobre o sujeito do ensino médio, [...] como são esses alunos, começaram a compreendê-los melhor, entendê-los melhor, eles têm suas dificuldades, eles são gente, têm outras coisas além de estudar. (OE12). 
Reconhecer o estudante em sua individualidade contribuiu para ele participar com sugestões nas atividades realizadas em sua escola e discutidas pelos docentes nos momentos em que ocorriam o planejamento e a execução delas. Isso porque o Pnem propunha discussões relacionadas ao protagonismo do jovem do ensino médio:

[...] a partir dos estudos do Pnem, foi visível a voz que o aluno ganhou. Ele deixou de apenas ser um ouvinte na sala de aula [...] passou a fazer parte desse grupo, das discussões, debates, expressando seus desejos, seus anseios, seus interesses vinculados à educação, e passou a representar isso na sua prática, participar. (OE6).

Durante sua realização, o Pnem motivava os docentes a desenvolverem atividades com a utilização de novas metodologias que se estenderam além da sala de aula, movimentando todos os que frequentavam a escola. $\mathrm{O}$ professor estava animado, empolgado e interessado no desenvolvimento de um trabalho diferenciado:

Quando estávamos fazendo a formação, desenvolvendo o programa, os professores estavam bem empolgados, começaram [...] a ver o aluno um pouco diferente, analisando a juventude nessa formação integral, ver os problemas que tinham na sala de aula [...] com um novo olhar, fazendo atividades diferentes. O programa deu ânimo para os professores trabalharem com o ensino médio (OE2).

As questões da juventude na escola não devem ser tratadas como problemas, mas como desafios a serem compreendidos e enfrentados. Assim, o caderno II da etapa I, O jovem como sujeito do ensino médio (Brasil. MEC. $\mathrm{SEB}, 2013 \mathrm{a})$, tratava das questões relacionadas à juventude, período em que os jovens se inserem na vida social, tanto na dimensão afetiva quanto na vida profissional, considerando, inclusive, cada qual na sua individualidade. Dessa forma, os professores foram levados a refletir sobre a condição dos alunos como sujeitos que vêm de contextos diferentes, com culturas marcadas pela diversidade e, muitas vezes, com uma vida estigmatizada pelas desigualdades sociais, tornando necessária a compreensão de quem com eles se relaciona e não a imposição de um parâmetro de "jovem ideal".

Finalmente, diante dos relatos dos orientadores de estudo, observa-se que a formação continuada é um processo que agrega novos conhecimentos ao docente, sendo necessária sua realização contínua ao longo da carreira. De acordo com a percepção dos orientadores de estudo, o Pnem contribuiu para a formação e mudanças nas práticas dos professores, permitindo reconhecer de forma diferente o estudante do ensino médio, buscando compreender sua realidade além do processo de ensino-aprendizagem e, posteriormente, planejar e desenvolver um trabalho direcionado à formação do sujeito.

\section{O término do Pnem diante da reforma do ensino médio}

A interrupção do Pnem foi mencionada com grande pesar pelos orientadores de estudo, pois a formação contribuiu para a ocorrência de 
mudanças no espaço escolar, a aproximação e o diálogo entre os docentes por meio da discussão, da reflexão, do planejamento e da problematização das dificuldades da escola.

Com a finalização do Pnem, os professores não dispõem mais de tempo específico para o diálogo e o planejamento, a troca de informações, a articulação de um trabalho coletivo, bem como para a discussão sobre as angústias que envolvem o grupo: "[...] era um momento que proporcionava o diálogo entre os professores, que conseguiam trocar algumas informações sobre o que trabalhavam e o que poderiam trabalhar juntos" (OE1); "[...] era um momento [...] não só para estudar e discutir o texto, mas era um momento em que o grupo estava reunido e compartilhando suas angústias" (OE10).

Diante dos comentários dos orientadores de estudo, observa-se a necessidade de uma formação permanente, em que os professores possam refletir criticamente sobre a prática, a fim de que esta possa ser melhorada constantemente.

Entre os orientadores de estudo entrevistados, o desejo pela continuidade da formação do Pnem foi unânime: "O Pnem era uma formação bem direcionada [...], deveria ser um programa constante na formação de professores [...] e sempre acompanhar a vida do professor, na sua formação, no seu trabalho para atuar com os alunos" (OE6). No entanto, ao mesmo tempo que havia o desejo pela continuidade do Pnem, ocorriam mudanças no cenário político nacional, que resultaram no impeachment da presidenta Dilma Roussef, em 2016. Mudanças políticas evidenciavam-se também no ensino médio, ocasionando decepção e pessimismo em relação à continuidade do Pnem, bem como de investimentos na formação continuada dos professores desse nível de ensino: "[...] com todas essas mudanças que estão ocorrendo hoje, eu não acredito que o Pnem continue, principalmente com os cortes financeiros que estão tendo na educação" (OE5).

Interrompido em 2015, o fim do Pnem ocorreu em 2016, com a Medida Provisória $\mathrm{n}^{\circ}$ 746, que, em 16 de fevereiro de 2017, passou a vigorar na Lei $\mathrm{n}^{\circ}$ 13.415/2017, instituindo a reforma do ensino médio. Para Silva e Sheibe (2017), a reforma, imposta inicialmente por medida provisória, deu-se de maneira autoritária, sem oportunidade de diálogo com a sociedade, cujas mudanças afetarão diretamente milhares de jovens brasileiros, diante da fragmentação do currículo escolar, negação do direito a uma formação básica comum, o que contribui ainda mais para reforçar as desigualdades educacionais. Amplamente contestada, trata-se de uma medida impositiva e arbitrária, evidenciando que as políticas educacionais são modificadas com a alternância de governo, geralmente utilizando-se de argumentos que têm o propósito de inovação e melhoria da qualidade na educação.

Para Moll (2017), as mudanças que vinham ocorrendo no ensino médio até então se direcionavam para que os docentes e a equipe pedagógica das escolas participassem mais efetivamente, evitando a ocorrência de mudanças homogeneizadoras que desconsiderassem a realidade cultural, social e produtiva local, contribuindo, assim, para a inserção dos jovens de forma respeitosa e diferenciada daquela hoje vivenciada. Moura e Lima Filho (2017) chamam a atenção para as experiências positivas ocorridas 
nas escolas antes da reforma do ensino médio, como a qualidade do ensino ofertado, com as condições necessárias, associadas "à concepção de formação humana integral, com a integração entre ciência, tecnologia, cultura e trabalho, como eixos norteadores do currículo" (Moura; Lima Filho, 2017, p. 120). Os autores ainda enfatizam os resultados positivos dos estudantes dessas escolas em avaliações como o Exame Nacional do Ensino Médio (Enem) e o Programa Internacional de Avaliação de Alunos (Pisa), em que as médias atingidas foram superiores às nacionais "e, em alguns casos, às de alunos de países da Organização para a Cooperação e Desenvolvimento Econômico (OCDE)" (Moura; Lima Filho, 2017, p. 120). No entanto, nem as mudanças que ocorriam no ensino médio, nem os resultados positivos entre os estudantes das escolas públicas foram sequer mencionados pelas autoridades que tanto apressavam e defendiam a proposta nos momentos que antecediam a aprovação da reforma do ensino médio.

Segundo Moura e Lima Filho (2017, p. 119), a elaboração da reforma do ensino médio contou com argumentos utilizados nos discursos oficiais do governo e de seus apoiadores, que difundiam a crítica à suposta "ineficiência e falta de flexibilidade" nesse nível de ensino da educação básica, especificamente na rede pública (nas redes estaduais e federal de educação profissional e tecnológica), reforçando um discurso para uma reforma urgente, inviabilizando um debate social e democrático. Segundo os autores, tais argumentos vinculavam-se à ideologia neoliberal, que censurava principalmente o presumido "currículo rígido", demandando que este fosse substituído por um "currículo enxuto e dinâmico", como itinerários formativos diferenciados, que valorizassem a escolha dos estudantes conforme seus interesses, incentivando, dessa forma, o protagonismo juvenil numa escola de tempo integral.

Além de modificar o texto da Lei de Diretrizes e Bases da Educação Nacional, Lei $n^{\circ}$ 9.394/1996, a lei da reforma do ensino médio (Brasil, 2017) desconsidera as práticas, os conhecimentos e as experiências dos docentes e discentes da educação básica, evidenciando que, infelizmente, tem sido um fato comum a cada mudança de governo a implementação de políticas educacionais que não levam em conta pesquisas e conhecimentos produzidos no campo educacional. Tal fato é confirmado por Gatti e Barreto (2009, p. 224), ao defenderem que "há necessidade de continuidade nessas políticas, e não as interrupções sucessivas nessas iniciativas como temos assistido ao longo dos últimos anos". As novas leis são elaboradas e aprovadas por sujeitos que, na maioria das vezes, não fazem ideia da realidade do ensino público brasileiro, ignorando os avanços não apenas das políticas, mas da prática até o momento. Aos docentes e estudantes, resta apenas a execução das leis que são aprovadas, restringindo-se a consumidores das novas políticas de governo.

É importante destacar que, em suas entrelinhas, a Lei no 13.415/2017 abre precedentes para a desvalorização da formação do professor. Em seu texto, a lei permite que profissionais não licenciados exerçam o magistério por meio do reconhecimento do "notório saber", ação que contribui para "a desvalorização, a desqualificação e o ataque à formação e profissionalidade dos docentes" (Moura; Lima Filho, 2017, p. 125) que atuam na educação básica, em especial no ensino médio. ${ }^{3}$
3 A lei da reforma do ensino médio considera como profissionais da educação básica os profissionais com notório saber, reconhecidos pelo sistema de ensino em que atuam, para ministrar conhecimentos segundo sua formação e experiência profissional, bem como sua formação técnica e profissional (Brasil, 2017). 
Considerar o notório saber acima da formação docente configura-se numa ação que, para Castilho (2017), demonstra a gravidade da situação que se apresenta à classe do magistério, marcada principalmente pela desvalorização da formação de professores e precarização da docência, comprometendo, consequentemente, a qualidade do ensino ofertado.

A formação do professor é indispensável porque há saberes e competências que são específicos da docência. Ensinar bem uma matéria não requer apenas saber o conteúdo - é preciso compreender o complexo processo de ensino-aprendizagem. (Castilho, 2017).

Diante do exposto, novos problemas podem contribuir ainda mais para a precarização geral das condições de trabalho, tanto para docentes licenciados quanto para aqueles com notório saber, para os quais, na maioria dos casos, a docência é uma atividade de renda complementar. O acúmulo de vínculos tende a contribuir para a intensificação do trabalho, com contratos temporários simultâneos e vulneráveis, pondo em risco a qualidade do processo de ensino (Moura; Lima Filho, 2017).

Segundo Lino (2017), a formação de professores foi ampliada no Brasil a partir dos anos 1940, com a criação das faculdades de Filosofia, Ciências e Letras e dos cursos de licenciatura. Nesse período, destaca a autora, inicia-se a formação de professores para o ensino secundário. No entanto, a presença de profissionais leigos ou sem formação pedagógica até o começo do século 21 ainda era significativa. Aos poucos, a legislação educacional implementou medidas para a superação da improvisação na formação de professores, e as ações de formação continuada tentavam minimizar esse quadro. No entanto, contraditoriamente, programas especiais forjavam a contratação em caráter emergencial de professores, com um mínimo de formação, para o ensino de disciplinas do segundo grau e do primeiro segmento do primeiro grau, ${ }^{4}$ nos anos de 1970 e 1980.

Mesmo diante de todos os esforços, a presença de professores leigos, sem a formação pedagógica específica, é reconhecida com preocupação, diante dos critérios para sua superação previstos na LDB, a qual, em seu artigo 62, estabelece que a formação de docentes para atuar na educação básica seja feita em nível superior, em curso de licenciatura de graduação plena, ao mesmo tempo que é novamente admitida na Lei $\mathrm{n}^{\circ} 13.415$ (Lino, 2017). A autora ainda destaca que "A luta pela formação dos professores no nível superior aliada à pesquisa não pode ser substituída por um 'notório saber' que traz de volta o professor leigo e, na prática, incentiva sua contratação" (Lino, 2017, p. 86).

As alterações no currículo para o "novo" ensino médio também impactam a carreira dos docentes e sua empregabilidade, uma vez que a obrigatoriedade ao longo do ensino médio se aplica às disciplinas de Língua Portuguesa, Matemática e Língua Inglesa - esta, sem garantia de se estender ao longo dos três anos do curso. Para as demais disciplinas, a proposta passa pelos itinerários formativos de acordo com as áreas do conhecimento, ${ }^{5}$ a serem definidos pelos sistemas de ensino, sem a obrigatoriedade de que todas as áreas componham o currículo. Tal ação pode contribuir ainda mais para a desqualificação do 
ensino médio público e para o aumento das desigualdades educacionais, uma vez que os processos seletivos para a entrada no ensino superior consideram as competências, habilidades e expectativas de aprendizagem das áreas de conhecimento que constam na Base Nacional Comum Curricular (Lino, 2017).

Após contextualização da importância da formação inicial docente, reporta-se à formação realizada por meio do Pnem, já que um dos objetivos do programa era a formação continuada de professores para elevar a qualidade da educação no ensino médio. A docência sem a formação compromete não apenas a atuação profissional, mas também a qualidade do ensino ofertado. Ao longo da profissão, o professor aprende na prática, mas os estudos das teorias que norteiam o ensino e a aprendizagem são indispensáveis, processo que tem sua significância reforçada para a ocorrência dos avanços educacionais, considerando que "nenhuma mudança na educação escolar pode ser levada a sério sem um efetivo projeto de formação inicial e continuada de professores e equipes gestoras das escolas" (Moll, 2017, p. 72).

Apesar da brevidade da existência do Pnem, o programa teve reconhecida sua importância, especialmente entre os docentes do ensino médio, visto que estes nem sempre são privilegiados com propostas de formação continuada. Acredita-se que os avanços e as melhorias na educação básica demandam uma série de fatores que incluem investimentos para a garantia básica da infraestrutura necessária, valorização profissional e programas que permitam a formação constante dos professores. Com o término do Pnem, finalizou-se uma proposta de formação em nível nacional, comum a todos os professores do ensino médio. Embora já tenha se passado mais de um ano da aprovação da Lei no 13.415/2017, ainda não há uma proposta de formação direcionada ao professor desse nível de ensino, a exemplo da formação ofertada pelo Pnem.

\section{Considerações finais}

Ao analisar a percepção dos orientadores de estudo sobre a formação continuada ofertada pelo Pnem, observa-se que essa teve reconhecida sua importância, tanto para o professor que atua no ensino médio quanto para o estudante em seu percurso formativo.

A formação direcionada aos professores do ensino médio foi um dos fatores fundamentais para a mobilização dos docentes a participarem do Pnem, tendo em vista que é raro uma formação ofertada especificamente a esse nível de ensino. Além do exposto, o certificado de 200 horas e a bolsa de estudo também contribuíram para a mobilização e a participação dos professores na formação. No entanto, o comparecimento do professor à escola além de sua carga horária constituiu-se numa dificuldade, principalmente em relação ao ajuste de horários, exigindo a reorganização de sua vida pessoal para participar do Pnem nos finais de tarde e aos sábados. Mesmo participando da formação, alguns docentes mostravam certa resistência em comparecer na escola fora dos horários de trabalho, especialmente diante da desvalorização profissional enfrentada pela categoria. A interrupção entre a primeira e a segunda etapa, realizada no início do ano de 2015, enfraqueceu a participação dos docentes, 
visto que os orientadores de estudo consideraram superior o desempenho dos professores no primeiro momento da formação. Coube a eles motivar e envolver o grupo novamente para que a formação retomasse seu ritmo e tivesse o aproveitamento desejado, demonstrando que o ideal é a formação ser planejada e realizada ao longo do ano letivo, tendo continuidade no ano subsequente, para que se configure num processo de formação permanente.

De modo geral, os orientadores de estudo reconheceram a importância da formação para o professor do ensino médio, pois essa cooperou para mudanças significativas no processo de ensino-aprendizagem, visualizadas nas práticas em sala de aula. Cite-se como um desses avanços o fato de os professores participantes passarem a desenvolver um trabalho interdisciplinar. Ainda: o processo avaliativo passou a ser realizado de modo diferenciado, considerando o estudante como um sujeito que possui uma individualidade, uma cultura e uma vida além da escola.

Mesmo com sua significância reconhecida, o Pnem teve vida curta, sendo interrompido em 2015. A certeza da finalização do programa deu-se em 2016, com a promessa da oferta de um ensino de qualidade em tempo integral, no qual o estudante escolheria o que cursar conforme sua área de interesse. No entanto, a lei apresenta nas entrelinhas que a rede de ensino ofertará o itinerário formativo conforme suas condições, demonstrando o início das desigualdades educacionais não apenas no momento de o aluno cursar o ensino médio, mas posteriormente, nas avaliações de acesso aos cursos superiores, uma vez que o Enem e os vestibulares elaboram suas provas tendo como suporte a Base Nacional Comum Curricular (BNCC). É importante destacar que, além de contribuir para as desigualdades educacionais entre os jovens que cursam o ensino médio, a Lei $\mathrm{n}^{\circ}$ 13.415/2017 coloca em risco a valorização dos docentes, por meio da contratação de profissionais com o notório saber reconhecido, não exigindo deles a formação mínima para a docência. Desconsiderar a formação docente é um descaso com o ensino e a aprendizagem. É também uma desvalorização dos profissionais da educação que se preparam para a docência por meio da formação inicial, seguindo ao longo de sua carreira com a formação continuada.

Lamenta-se que a cada novo governo novas políticas sejam implementadas com a promessa de solucionar todos os problemas da educação. O Pnem, como mostram os dados analisados neste trabalho, teve seu reconhecimento pela promoção de mudanças significativas no ensino médio. No entanto, após sua finalização, o que se observa são muitas controvérsias. Nestes tempos preocupantes e sombrios, só com muita resistência se mantém o sonho de uma educação de qualidade e igual para todos.

\section{Referências}

ANDRÉ, M. Formação de professores: a constituição de um campo de estudos. Educação, Porto Alegre, v. 33, n. 3, p. 174-181, set./dez. 2010. 
ARAÚJO, C. M.; ARAÚJO, E. M.; SILVA, R. D. Para pensar sobre a formação continuada de professores é imprescindível uma teoria crítica de formação humana. Cadernos Cedes, Campinas, v. 35, n. 95, p. 57-73, jan./abr. 2015.

BRASIL. Lei $\mathrm{n}^{\circ}$ 13.415, de 16 de fevereiro de 2017. Altera as Leis $\mathrm{n}^{\circ} \mathrm{s}$ 9.394, de 20 de dezembro de 1996, que estabelece as diretrizes e bases da educação nacional, e 11.494, de 20 de junho 2007, que regulamenta o Fundo de Manutenção e Desenvolvimento da Educação Básica e de Valorização dos Profissionais da Educação, a Consolidação das Leis do Trabalho - CLT, aprovada pelo Decreto-Lei $\mathrm{n}^{\circ} 5.452$, de $1^{\circ}$ de maio de 1943, e o Decreto-Lei no 236, de 28 de fevereiro de 1967; revoga a Lei $\mathrm{n}^{\mathrm{o}}$ 11.161, de 5 de agosto de 2005; e institui a Política de Fomento à Implementação de Escolas de Ensino Médio em Tempo Integral. Diário Oficial da União, Brasília, DF, 17 fev. 2017. Seção 1, p. 1.

BRASIL. Ministério da Educação (MEC). Pacto Nacional pelo Fortalecimento do Ensino Médio. Brasília: MEC, [s.d.]. Disponível em: <http://pactoensinomedio.mec.gov.br/index.php?option=com_ content\&view $=$ article\&id=22 > . Acesso em: 9 jun. 2016.

BRASIL. Ministério da Educação (MEC). Portaria no 1.140, de 22 de novembro de 2013. Institui o Pacto Nacional pelo Fortalecimento do Ensino Médio e define suas diretrizes gerais, forma, condições e critérios para a concessão de bolsas de estudo e pesquisa no âmbito do ensino médio público, nas redes estaduais e distrital de educação. Diário Oficial da União, Brasília, DF, 25 nov. 2013. Seção 1, p. 24.

BRASIL. Ministério da Educação (MEC). Conselho Nacional de Educação (CNE). Câmara de Educação Básica (CEB). Resolução no 2, de 30 de janeiro de 2012. Define diretrizes curriculares nacionais para o ensino médio. Diário Oficial da União, Brasília, DF, 31 jan. 2012. Seção 1, p. 20.

BRASIL. Ministério da Educação (MEC). Secretaria de Educação Básica (SEB). Formação de professores do ensino médio: o jovem como sujeito do ensino médio: etapa I: caderno II. Curitiba: UFPR/Setor de Educação, 2013a.

BRASIL. Ministério da Educação (MEC). Secretaria de Educação Básica (SEB). Formação de professores do ensino médio: avaliação no ensino médio: etapa I: caderno VI. Curitiba: UFPR/Setor de Educação, 2013b.

BRASIL. Ministério da Educação (MEC). Secretaria de Educação Básica (SEB). Formação de professores do ensino médio: organização do trabalho pedagógico no ensino médio: etapa II: caderno I. Curitiba: UFPR/Setor de Educação, 2014.

CANDAU, V. M. F. Formação continuada de professores: tendências atuais. In: REALI, A. M. M. R.; MIZUKAMI, M. G. N. Formação de professores: tendências atuais. São Carlos: Ed. da UFSCar, 1996. p. 139-152.

CASTILHO, D. Reforma do ensino médio: desmonte na educação e inércia do enfrentamento retórico. 2017. Disponível em: <https:// 
www.pragmatismopolitico.com.br/2017/02/reforma-do-ensino-mediodesmonte-educacao-inercia.html>. Acesso em: 03 jan. 2016.

FREIRE, P. Educação e mudança. Rio de Janeiro: Paz e Terra, 1979.

FREIRE, P. Pedagogia da autonomia: saberes necessários à prática educativa. São Paulo: Paz e Terra, 1996.

GATTI, B. A.; BARRETO, E. S. S. Professores do Brasil: impasses e desafios. Brasília: UNESCO, 2009.

GATti, B. A.; BARRETO, E. S. S.; ANDRÉ, M. E. D. A. Políticas docentes no Brasil: um estado da arte. Brasília: Unesco, 2011.

LINO, L. A. As ameaças da reforma: desqualificação e exclusão. Retratos da Escola, Brasília, v. 11, n. 20, p. 75-90, jan./jun. 2017.

MIZUKAMI, M. N. Docência, trajetórias pessoais e desenvolvimento profissional. In: REALI, A. M. M. R.; MIZUKAMI, M. G. N. Formação de professores: tendências atuais. São Carlos: Ed. da UFSCar, 1996. p. 59-89.

MOLL, J. Reformar para retardar: a lógica da mudança no EM. Retratos da Escola, Brasília, v. 11, n. 20, p. 61-74, jan./jun. 2017.

MOURA, D. H.; LIMA FILHO, D. L. A reforma do ensino médio: regressão de direitos sociais. Retratos da Escola, Brasília, v. 11, n. 20, p. 61-74, p. 109-129, jan./jun. 2017.

SILVA, E. M. A.; ARAUUO, C. M. A. Reflexão em Paulo Freire: uma contribuição para a formação continuada de professores. In: COLÓQUIO INTERNACIONAL PAULO FREIRE, 5., 2005, Recife. Anais... Recife, 2005. Disponível em: <http://189.28.128.100/nutricao/docs/Enpacs/pesquisa Artigos/reflexao_em_paulo_freire_2005.pdf >. Acesso em: 3 jan. 2016.

SILVA, M. R.; SHEIBE, L. Reforma do ensino médio: pragmatismo e lógica mercantil. Retratos da Escola, Brasília, v. 11, n. 20, p. 19-31, jan./jun. 2017.

ZARDO MORESCHO, S. M. Formação continuada de professores: a percepção do orientador de estudo sobre o Pnem na Gered de Chapecó, SC. Dissertação (Mestrado em Educação) - Universidade Comunitária da Região de Chapecó, Chapecó, 2017.

Recebido em 9 de setembro de 2018.

Aprovado em 4 de fevereiro de 2019. 